\title{
Sporobolus spicatus, a potential turf grass under the climatic conditions of United Arab Emirates
}

\author{
Muhammad Zamin ${ }^{*}$, Abdul Mateen Khattak ${ }^{1}$, Mohammed A. Salem Alyafei², Muhammed \\ Sajid', Muhammad Shakur, Shahen Shah4, Ikramullah Khan², Haroon Ur Rashid5 and \\ Shafiulla ${ }^{6}$
}

${ }^{1}$ Department of Horticulture, Faculty of Crop Production Sciences, The University of Agriculture, Peshawar, Pakistan

${ }^{2}$ Department of Aridland Agriculture, College of Food and Agriculture, United Arab Emirates University, Al Ain 15551, United Arab Emirates

3Department of Plant Protection, The University of Agriculture, Peshawar, Pakistan

4Department of Agronomy, The University of Agriculture, Peshawar, Pakistan

5Department of Agriculture, University of Haripur, Pakistan

${ }^{6}$ Department of Irrigation, Dubai Municipality, Dubai, United Arab Emirates

\begin{abstract}
Different accessions of Sporobolus spicatus were tested for the possible use in the landscaping sector of United Arab Emirates. In this regards, fifty accessions of $S$. spicatus were screened against five salinity levels of $15,30,45,60$ and $75 \mathrm{dSm}^{-1}$ at $3 \mathrm{~cm}$ mowing height. Significant variations were found among the treatment for various characters of leaf colour, fresh and dry weight. Most of the accessions of the grass tolerated up to $45 \mathrm{dSm}^{-1}$, without compromising on quality. Further increase in salinity, most of the accessions ceased to grow, except a few accessions which survived even at salinity levels of $75 \mathrm{dSm}^{-1}$. Many of the grasses exhibit better performance than Paspalam vaginatum, the prevailing commercial turf grass in UAE (used as control in this instance). As a whole accessions $45 \mathrm{~S}$, $18 \mathrm{~S}, 35 \mathrm{~S}$ and $37 \mathrm{~S}$ showed salinity tolerance at $3 \mathrm{~cm}$ mowing height and maintaining quality up to the acceptable level. Based on their tolerance to salinity and better performance, these accessions are recommended for turf use in public landscaping.
\end{abstract}

Key words: Native grass; salinity; turf; sustainable landscaping

\section{Introduction}

Turf grasses are used to beautify properties in urban areas mostly in desert areas where water scarcity and salinity are the most important issues (Al-Shehhi et al., 2010). To maintain quality turf grass, huge amount is spent on desalination of saline water. There are native plants growing under high saline conditions which can be grown using salt water and requiring minimum maintenance leading to sustainable landscaping (Pessarakli, 2015).

\footnotetext{
Received 17 November 2017; Accepted 28 December 2017; Published 02 January 2018

*Corresponding Author

Muhammad Zamin

Department of Horticulture, Faculty of Crop Production Sciences, The University of Agriculture, Peshawar, Pakistan

Email: zaminhort@yahoo.com

(OThis article is open access and licensed under the terms of the Creative Commons Attribution License (http://creativecommons.org/licenses/by/4.o/) which permits unrestricted, use, distribution and reproduction in any medium, or format for any purpose, even commercially provided the work is properly cited. Attribution - You must give appropriate credit, provide a link to the license, and indicate if changes were made.
} 
Some of the indigenous grasses have quality indices, which are better than prevailing varieties (Viggiani et al., 2015). Hence, we need to identify these salt tolerant grasses and introduce in landscaping so that sustainability in landscaping field could be achieved (Ashraf et al. 2012). Since, $S$ spicatus belong to UAE flora, it is suitable for the rehabilitation of degraded salt-affected habitats (El-Keblawy et al., 2009). United Arab Emirates has vast brackish (highly saline) ground water resources. S. spicatus is growing in coastal sabhkas, with soil salinities above sea water, therefore, direct sea water can be used for irrigation (Environment Agency Abu Dhabi, 2009; Murad et al., 2007). Using halophytic (salt loving plants) grasses in landscaping under high saline conditions also will save valuable fresh water for domestic use (Khan and Weber, 2006). Therefore, the study was aimed to screen various accessions of $S$. spicatus from different parts of the UAE, for turf use.

\section{Materials and methods}

The experiment was conducted in Abu Dhabi, UAE during the year 2014. The experiment was laid out in RCBD with two factors and 4 replications. Factor 1 consists of 5 Salinity levels $\left(15,30,4560\right.$, and $\left.75 \mathrm{dSm}^{-1}\right)$ and tap water as control, while factor 2 included 50 accessions of Sporobolus spicatus and Passpallum vaginatum was used as a control.

\section{Grass establishment}

50 accessions of Sporobolus spicatus grass were grown in $10 \mathrm{~cm}$ plastic pots in a medium composed of mixture of sand and compost (9:1) using the same concept of Uddin et al. (2009) and maintained till establishment; pots fully covered with grass. Then the pots were placed in shade house to protect the grasses from unexpected wind and other environmental impacts.

\section{Preparation of salt solution}

The water tank was partially filled with water and then salt $(99 \% \mathrm{NaCl})$ was dissolved gradually. Electrical conductivity (EC) was checked with the help of EC meter until it reached the required salinity level.

\section{Procedure}

Five salinity $(\mathrm{NaCl})$ levels were applied to all the accessions after tap water application via drip irrigation using the concept of Uddin et al. (2009). The saline water application was incremental and once the treatment of a specific salinity over, the next salinity level was applied to the same grasses. Drip lines were installed with a single emitter per pot connected to 500 liter water tanks. Pots were irrigated at 200ml per pot twice a day. Flushing of the pots were done with fresh water on weekly basis to avoid salt accumulation. (Municipality of Abu Dhabi City, 2012).

\section{Acclimatization}

After the fresh water application and between each two treatments, salt $(\mathrm{NaCl})$ was added to the water tank with an increment of $5 \mathrm{dSm}^{-1}$ every three days till reaching the required salinity level.

After completion of acclimatization process during each treatment, the grasses were clipped at $3 \mathrm{~cm}$ height and discarded without collecting any data. Then starting the relevant salinity level and maintaining for two weeks. At the end of two weeks, data were taken for the following parameters.

\section{Parameters}

1) Lead colour (1-10)

2) Fresh weight (g)

3) Dry weight (g)

4) Internodes length (mm)

The response of various grass accessions was recorded and shown against each treatment for all variables. All the possible interactions were recorded as well. The data were analysed using Statistix 8.1 software applying the analysis of variance (ANOVA) technique (Steel et al., 1980). ANOVA was used to see the variance among the means. In case the differences were significant, the means were further subjected to Tukey test to observe the differences between individual means (Abdi and Williams, 2010). Based on the above data the grass accessions with high salinity tolerance were selected and recommended for further multiplication.

\section{Results and discussion \\ Leaf colour (1-10)}

The leaf colour of different accessions was significantly $(\mathrm{P} \leq 0.001)$ affected by salinity levels. However, the interaction between salinity and accessions was also significant. According to Figure 1, leaf colour quality drop was maximum at $15 \mathrm{dSm}^{-1}$ and then a slow decrease was observed in colour till $45 \mathrm{dSm}^{-1}$. At further higher salinity levels most of the accessions did not survive or had low colour rating. The promising accessions included $45 \mathrm{~S}$, 
$18 \mathrm{~S}, 35 \mathrm{~S}, 4 \mathrm{~S}$ and $37 \mathrm{~S}$ which were at par with control grass. As shown in Fig. 1.1 the accessions treated with tap water (control) showed excellent performance by maintaining quality green colour (i.e.10 out of 10). However, at salinity level of $15 \mathrm{dSm}^{-1}$, the colour quality rating reduced, whereby the best performing accessions were $1 \mathrm{~S}$ (9.75), $2 \mathrm{~S}$ (9.25) and $3 \mathrm{~S}(9)$ followed by $4 \mathrm{~S}, 13 \mathrm{~S}$ (8.5) which gave the same colour rating of control grass $(51 \mathrm{P})$ while ecotype $29 \mathrm{~S}$ gave the lowest (4) quality rating of leaf colour. All the remaining accessions were above average 5 (of 10). At salinity level of $30 \mathrm{dm}^{-1}$, the top quality leaf colour rating was found in ecotype $45 \mathrm{~S}$ (8.25), followed by $35 \mathrm{~S}$, $36 \mathrm{~S}, 4 \mathrm{~S}$ (7.75), while ecotype $31 \mathrm{~S}$ was the lowest (3) in terms of leaf colour quality. 60\% accessions gave leaf colour quality rating in the range of 5.75 and 6.75 . At salinity level of $45 \mathrm{dSm}^{-1}$, accessions $37 \mathrm{~S}$ and $3 \mathrm{~S}$ gave maximum (7.5) leaf colour rating, followed by accessions $2 \mathrm{~S}, 12 \mathrm{~S}, 36 \mathrm{~S}$ and $4 \mathrm{~S}$ (with 7.25 colour rating each), while minimum (3.63) leaf colour rating was recorded in ecotype $17 \mathrm{~S}$. The control grass gave quality rating of 6.5 . At salinity level of 60 and $75 \mathrm{dSm}^{-1}$, most of the accessions expired. However, the ones that survived, gave acceptable quality rating such that at $60 \mathrm{dSm}^{-1}$ some accessions were $18 \mathrm{~S}, 26 \mathrm{~S}(6), 2 \mathrm{~S}, 4 \mathrm{~S}$ (5.88), 21S (5.75), 27S (5.5), 38S, 45S (5.38), and $19 \mathrm{~S}(5.25)$, and at $75 \mathrm{dSm}^{-1}$ ecotype $45 \mathrm{~S}$ (5.38) gave top colour rating.

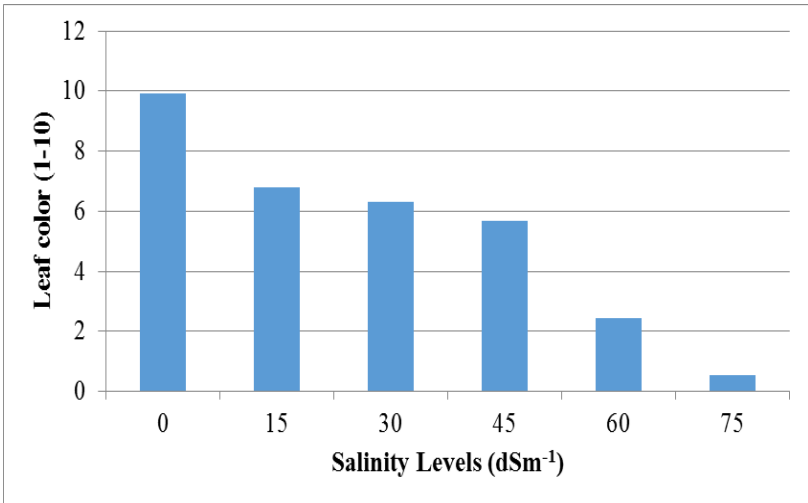

Fig. 1. Effect of salinity levels (o to $75 \mathrm{dSm}^{-1}$ ) on leaf colour.

As indicated in Fig. 1, leaf colour is negatively affected by increasing salinity levels. The highest value for green colour was noticed at zero salinity level and exponentially decreased up to $30 \mathrm{dSm} \mathrm{Sm}^{-1}$ and then a slow affect is seen at higher levels. It may be due the reason that the ecotype adjusts itself and get resistant to high salinity level. Romani et al. (2002) found that all the accessions were significantly different from each other while evaluating 226 native accessions. In most of the accessions, colour rating was far better than control grass. Our results are in line with the findings of Pooya et al. (2013) who also found that native grasses were better in leaf colour quality than commercial cultivars. Similarly, Viggiani et al. (2015) also found native ecotypes performing better than commercial cultivars in terms of colour index, growth rate and green cover.

\section{Fresh weight (g)}

According to Fig. 2, the fresh weight of different accessions was significantly $(\mathrm{P} \leq$ 0.001) affected by salinity levels. However, the interaction between salinity levels and accessions was also significant (Fig. 2.1). Figure 2 shows that fresh weight of all the accessions was affected by increasing salinity such that grasses grown at control (tap water) produced maximum fresh weight while increasing the salinities affected the growth and thus reduced fresh weight. Promising accessions with higher fresh weights included $46 \mathrm{~S}, 35 \mathrm{~S}, 39 \mathrm{~S}, 41 \mathrm{~S}, 38 \mathrm{~S}$, $37 \mathrm{~S}, 45 \mathrm{~S}$ and $30 \mathrm{~S}$ which gave more fresh weight than control grass (51P). At salinity level of $15 \mathrm{dSm}^{-1}, 46 \mathrm{~S}$ was the best performing ecotype with $0.89 \mathrm{~g}$ fresh weight, followed by $43 \mathrm{~S}$ (0.738g), while ecotype $1 \mathrm{~S}$ gave minimum (0.115g) fresh weight. 60\% accessions gave fresh weight in the range of 0.288 to $0.56 \mathrm{~g}$. Similarly, at $30 \mathrm{dSm}{ }^{-1}$ the fresh weight was reduced as compared to $15 \mathrm{dSm}^{-1}$ in various ecotype whereby the maximum dry weight was recorded in $42 \mathrm{~S}$ (0.695g) followed by $41 \mathrm{~S}$ (0.628g), 39S (0.615g), 38S (0.563g), 35S (0.56g) and $37 \mathrm{~S}(0.5 \mathrm{~g})$. Minimum (0.12g) fresh weight was recorded for ecotype $12 \mathrm{~S}$, while control grass $(51 \mathrm{P})$ gave fresh weight of $0.13 \mathrm{~g}$. The remaining $60 \%$ accessions were in the range of 0.218 to $0.38 \mathrm{~g}$. At salinity level of $45 \mathrm{dSm}^{-1}$, the top fresh weight producing accessions included $3 \mathrm{~S}(0.388 \mathrm{~g}), 30 \mathrm{~S}$ (0.37g), 29S (0.36g), 17S (0.338g) and 5S (0.33g), while ecotype $12 \mathrm{~S}$ gave minimum (0.07g) fresh weight. The salinity level of $60 \mathrm{dSm}{ }^{-1}$ severely affected the accessions and most of them did not survive. Among the surviving accessions, $18 \mathrm{~S}$ produced maximum $(0.245 \mathrm{~g})$ fresh weight, followed by ecotype $35 \mathrm{~S}(0.225 \mathrm{~g})$, while ecotype $41 \mathrm{~S}$ gave minimum (0.065g) fresh weight. Similarly, at $75 \mathrm{dSm}^{-1}$, only a few accessions including $18 \mathrm{~S}, 45 \mathrm{~S}, 21 \mathrm{~S}, 29 \mathrm{~S}, 35 \mathrm{~S}$ 
and $30 \mathrm{~S}$ could survive producing $0.135 \mathrm{~g}$, 0.125g, 0.113g, 0.11g, 0.103g and 0.098g fresh weights respectively. The control grass did not survive either at this salinity level. Uddin et al. (2009) also found significantly different responses of all the accessions they studied. These results are in line with Naz et al. (2010), who found the similar reduction in weight with increasing salinities. A sharp decline was observed for fresh weight at salinity levels from zero up to $15 \mathrm{dSm}^{-1}$ but the decline in case of $30 \mathrm{dSm}^{-1}$ to $45 \mathrm{dSm}^{-1}$ was comparatively less. It might be due to the fact that grasses could manage the small rise in salinity without suffering much as stated by $\mathrm{Hu}$ et al. (2012). However, the trend in fresh weight decline was gradual till salinity level of $45 \mathrm{dS} / \mathrm{m}$ and after that it decreased with higher rate of salt. Zhang et al. (2013) and Barhoumi et al. (2007) observed that fresh weight was inversely proportional to salinity. These results are in confirmation to them. Their results showed that plant growth was inversely proportional to salinity levels and there was a linear decrease in shoot growth with the increase in the growing medium salinity.

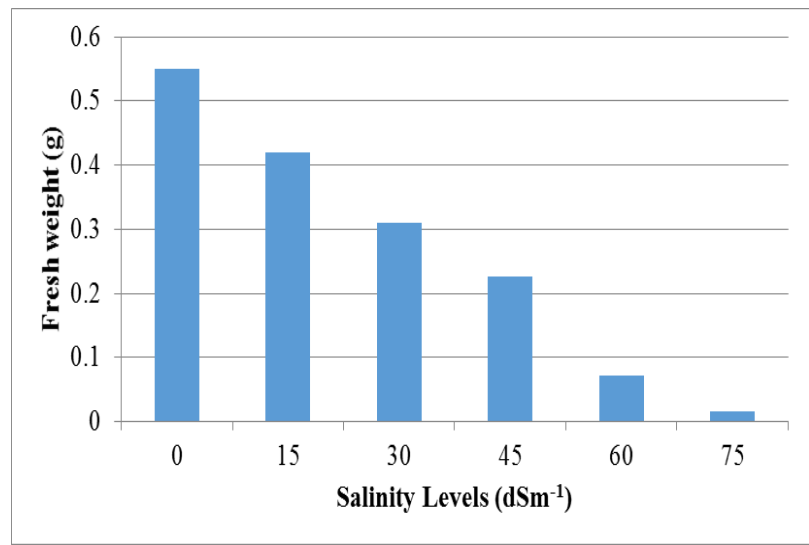

Fig. 2. Effect of salinity levels (o to $75 \mathrm{dSm}^{-1}$ ) on fresh weight (g).

\section{Dry weight (g)}

The dry weight of different accessions was significantly $(\mathrm{P} \leq 0.001)$ affected by salinity (Fig 3). Similarly, interaction between salinity and accessions was also significant (Fig. 3.1). According to figure 3 , the results followed almost a similar trend as those of fresh weight except that the drop of dry weight from 30 to $45 \mathrm{dSm}^{-1}$ salinity level was sharper than the fresh weight. Accessions such as $46 \mathrm{~S}, 35 \mathrm{~S}, 38 \mathrm{~S}$ and $45 \mathrm{~S}$ that gave good results for fresh weight also performed well in case of dry weight.
Approximately 20\% of accessions performed better than control grass $(51 \mathrm{P})$ at higher salinity levels. At salinity treatment of $15 \mathrm{dSm}^{-1}$, maximum (0.258g) dry weight was produced by accessions $42 \mathrm{~S}$ and $41 \mathrm{~S}$, followed by $46 \mathrm{~S}$ (0.253g), while minimum dry weights were produced by $1 \mathrm{~S}(0.048 \mathrm{~g}) .60 \%$ of accessions produced dry weight between 0.115 to 0.200 . At salinity of $30 \mathrm{OSm}{ }^{-1}$ the highest (0.248g) dry weight was provided by ecotype $42 \mathrm{~S}$, while minimum (0.023g) was produced by ecotype $12 \mathrm{~S}$. The control grass gave dry weight of $0.053 \mathrm{~g}$ while $60 \%$ accessions produced dry weight between 0.085 and $0.150 g$. The accessions performed differently at salinity of $45 \mathrm{dSm}^{-1}$ and the top ten accessions were $17 \mathrm{~S}$ (0.215g), 18S (0.198g), 24S (0.173g), 4S (0.170g), 20S (0.150g), 44S (0.150g), 38S (0.145g), 22S (0.138g), 30S (o.135g) and 21S (0.130g), while ecotype $12 \mathrm{~S}$ produced minimum (0.033g) dry weight. At salinity level of $6 \mathrm{odSm}^{-1}$, most of the accessions expired and thus did not produce any dry weight. Only a few accessions survived and produced dry weight including $27 \mathrm{~S}$ (0.153g), 44S (o.115g), $35 \mathrm{~S}$ (0.100g) while lowest dry weight was found in $41 \mathrm{~S}(0.038 \mathrm{~g})$. Likewise, salinity of $75 \mathrm{dSm}^{-1}$ also severely affected the performance of accessions and only a few survived producing dry weight such as $45 \mathrm{~S}$ (0.098g), 18S (0.070g), 29S (0.065g), 35S (0.063g), 30S (0.060g), 37S (0.058g) and 21S (0.058g). Our data comply with findings of Mintenko and Smith (2001) who found that the growth of native grasses reduced at higher salinity levels. Dry weight shows the growing status of grass and has inversely proportional to increasing salinity levels. As a whole, all the accessions suffered weight loss with increasing salinity levels upto75 $\mathrm{dSm}^{-1}$. The results are in line with the findings of Naz et al. (2010) and Zhang et al. (2013) who also observed that dry weight declined with increasing salinity levels. On the other hand, Uddin et al. (2009) found 50\% reduction in growth at salinity level of $39.8 \mathrm{dSm}^{-1}$, whereas, in our case less than $50 \%$ growth reduction occurred even at $45 \mathrm{dSm}^{-1}$ salinity level. Marcum (2006) also found similar pattern of results on Bermuda grass cultivars. According to their results, salinity ranging from 26 to $40 \mathrm{dS} \mathrm{m}{ }^{-1}$ caused $50 \%$ reduction in shoot dry weight, indicating a wide range in salinity tolerance within this species. 


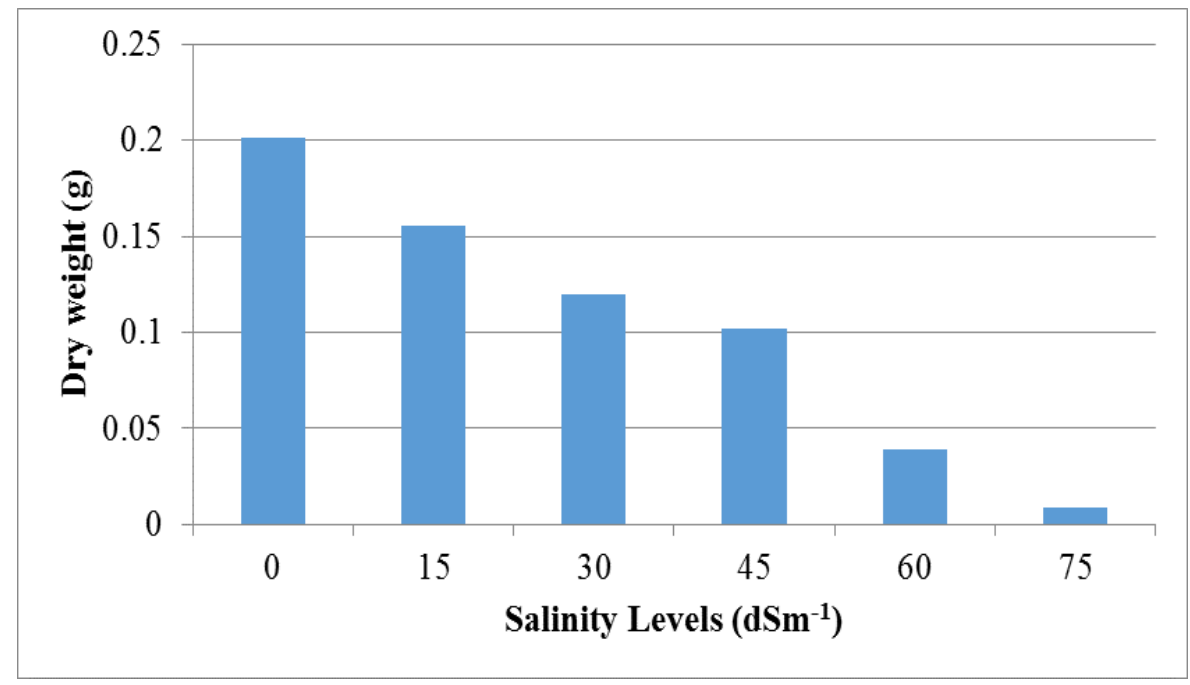

Fig. 3. Effect of salinity levels (o to $75 \mathrm{dSm}^{-1}$ ) on dry weight (g).

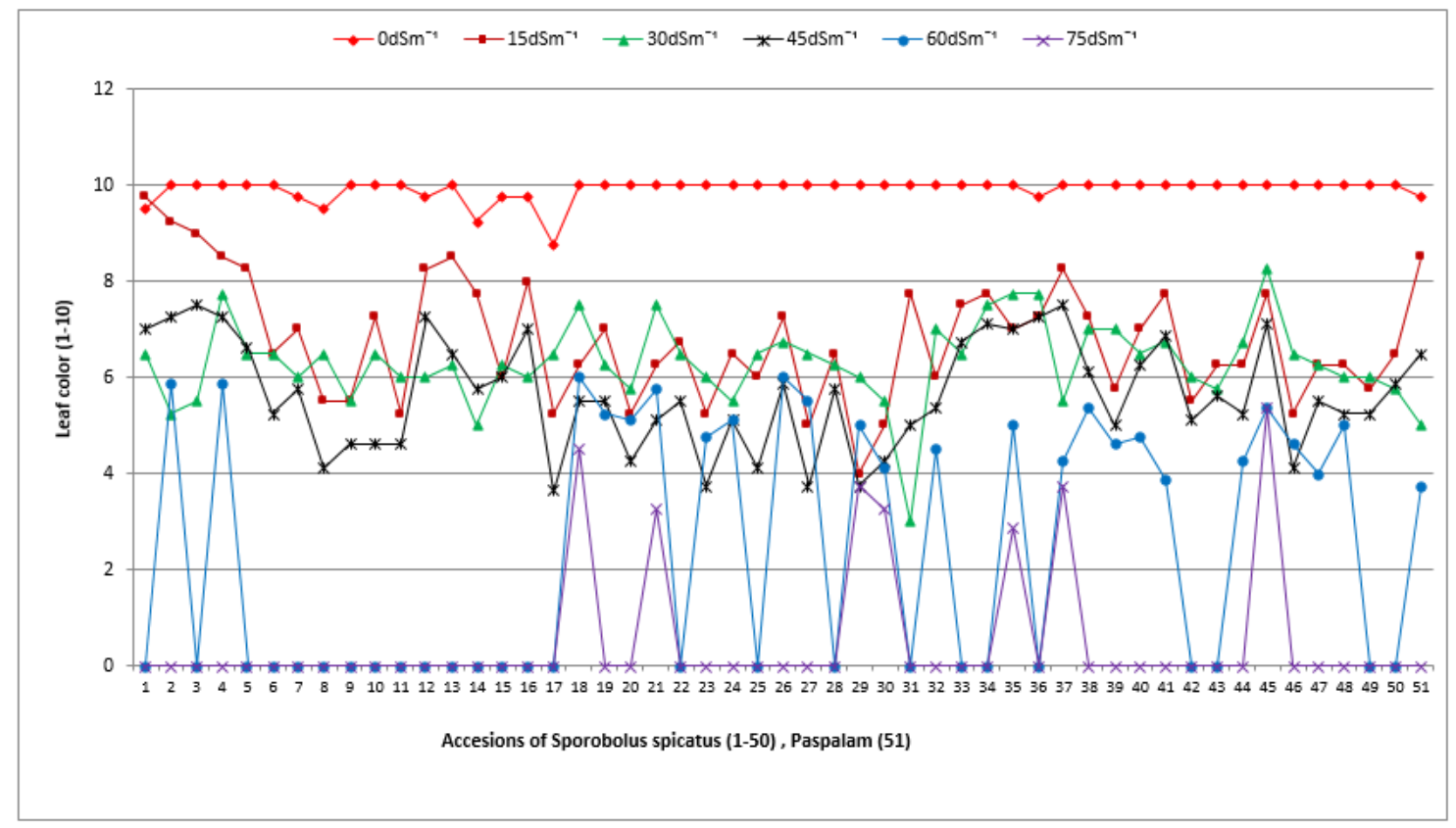

Fig. 1.1. Effect of salinity levels (o to $75 \mathrm{dSm}^{-1}$ ) on leaf colour of different Sporobolus spicatus accessions (1-50) and Paspalum (51; control). Leaf colour refers to the green colour of the grass accessions and is ranged 1-10, where 1 means dry leaves and 10 represents lush green colour. $o$ values mean the accessions did not survive. 


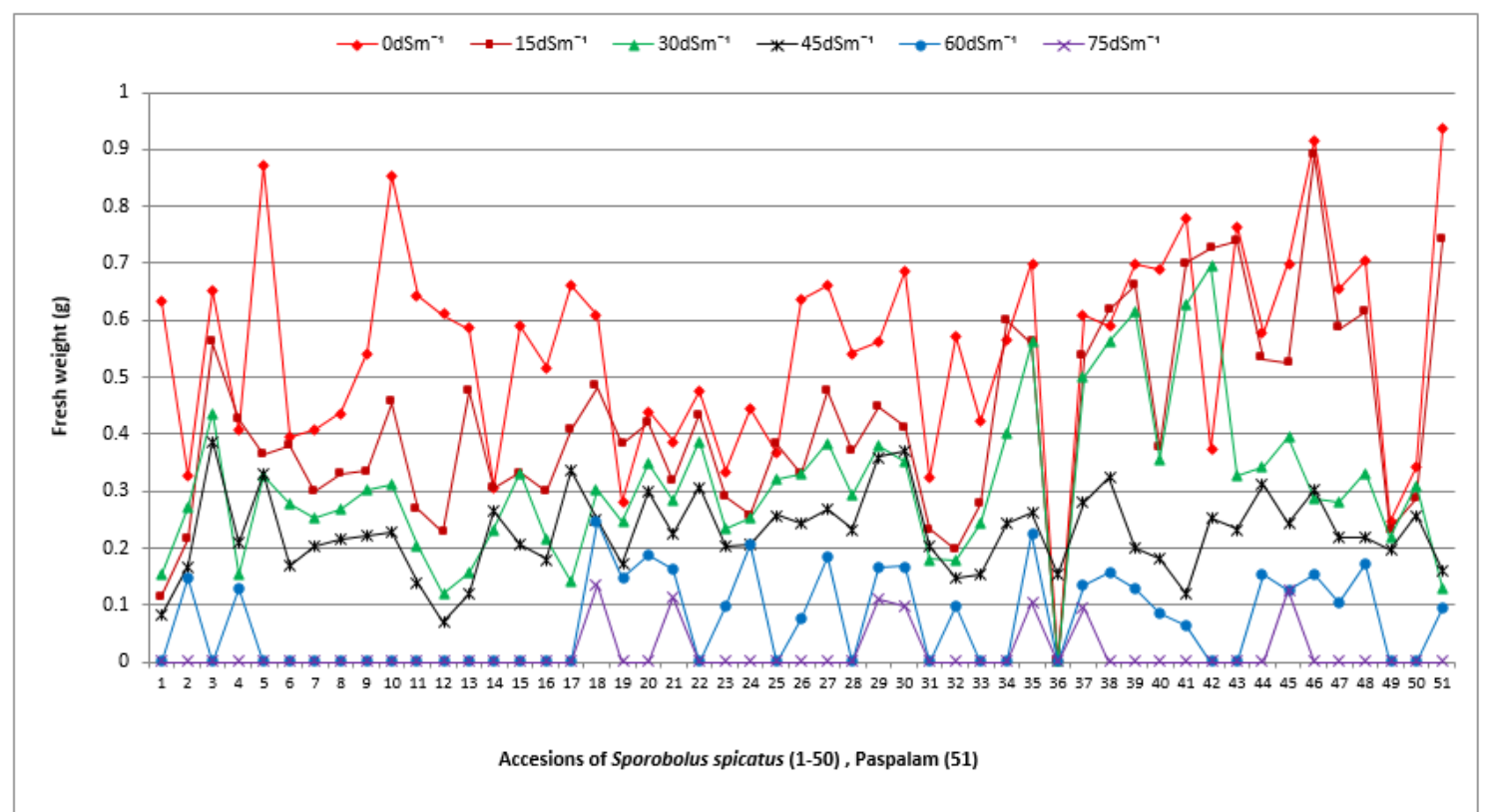

Fig. 2.1 Effect of salinity levels (o to $75 \mathrm{dSm}^{-1}$ ) on the fresh weight of different Sporobolus spicatus accessions (1-50) and Paspalum (51; control). Fresh weight refers to the weight of total biomass produced per clipping per pot. $\mathrm{o}$ values mean the accessions did not survive.

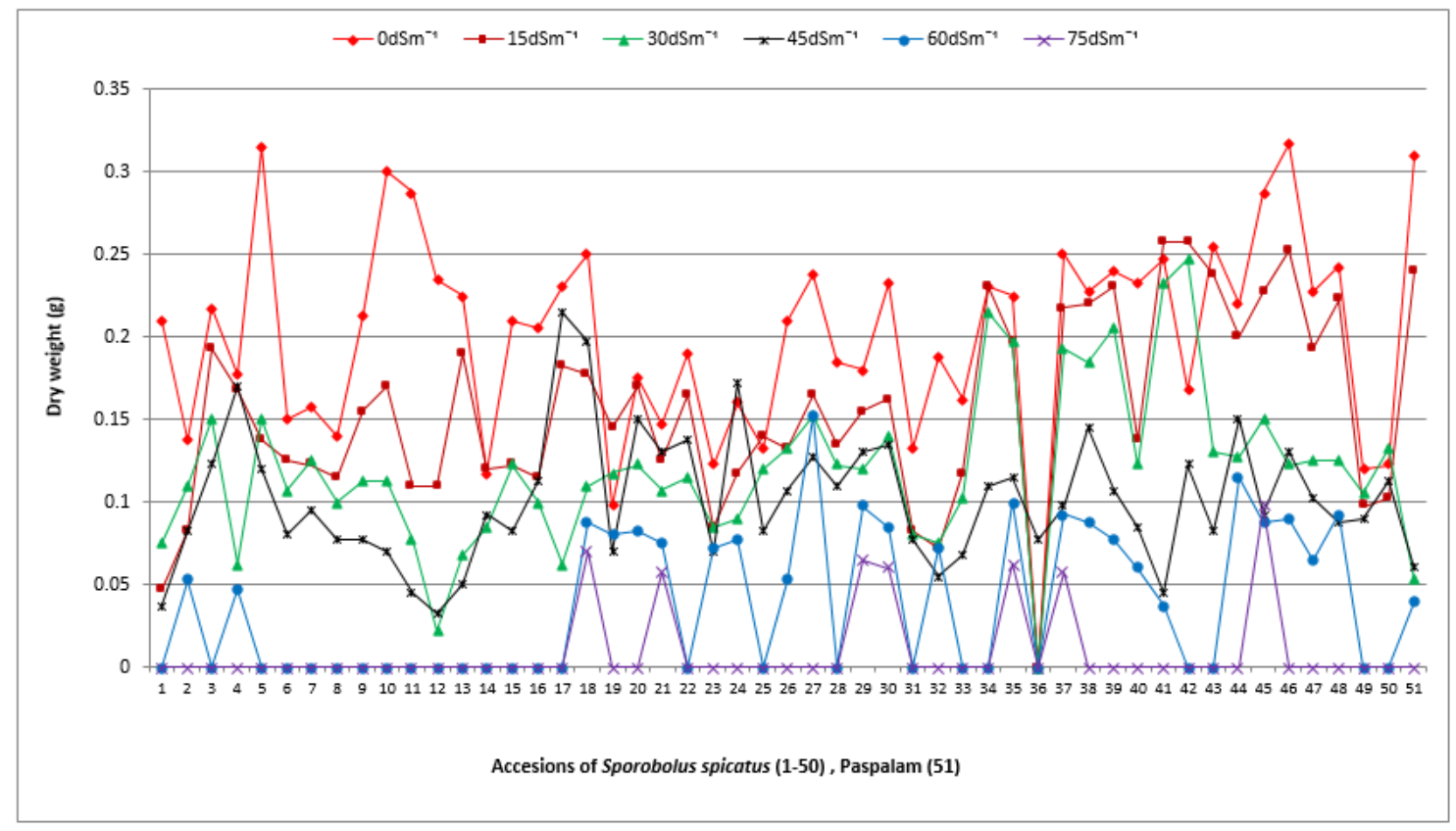

Fig. 3.1. Effect of salinity levels (o to $75 \mathrm{dSm}^{-1}$ ) on dry weight of different Sporobolus spicatus accessions (150) and Paspalum (51; control). Dry weight refers to the weight of total biomass produced per clipping per pot after oven drying. $\mathrm{O}$ values mean the accessions did not survive.

\section{Conclusion and recommendations}

Following conclusions are made from the study:

1. Sporobolus spicatus species have accessions/ecotypes with significant variations and variabilities, which show that they have adoptability potential.
2. The best performing accessions were found $45 \mathrm{~S}, 18 \mathrm{~S}, 35 \mathrm{~S}$ and $37 \mathrm{~S}$ which can be used for turf purpose.

3. The salinity issue of UAE could be managed by using native grasses in public landscape, where the sea water also can be used in worse conditions. 
4. Further research work is recommended on $S$. spicatus grasses to find out their potential as donors of salt tolerant characters for improving other crops in breeding program.

\section{Acknowledgements}

This paper is a part of my Thesis for the fulfilment of Degree of Ph.D.

I am thankful to Dr. Kenneth B. Marcum and Dr. Abdul Muhsin Salim, Department of Aridland Agriculture, Faculty of Food and Agriculture, UAE University for their support in providing me the opportunity of conducting research under their supervision.

\section{Authors' contributions}

1. Mr. Muhammad Zamin (Main author conducting the research)

2. Prof. Dr. Abdul Mateen Khattak (Supervisor)

3. Prof. Dr. Abdul Mohsin Salim (Cosupervisor)

4. Dr Muhammad Sajid (Research committee member)

5. Mr. Muhammad Shakur (Technical and logistic support during data collection)

6. Mr. Haroon Ur Rashid (Support during ecotypes collection)

7. Dr Shahen Shah (Technical support during analysis)

8. Dr. Ikramullah (Research fellow)

9. Mr. Shafiullah (Technical support)

\section{References}

Abdi, H. and Williams, L. J. (2010). Tukey's honestly significant difference (HSD) test. P. 1-5. In: Salkind, N. (eds.) Encyclopedia of Research Design. Thousand Oaks, CA.

Al-Shehhi, A.M.H., I.A. Khan, F. Al-Said, M.L. Deadman, S. Alkanjari, and T. Ahmad. 2010. Evaluation of warm season turfgrass under different irrigation regimes in arid region. Notulae Sci. Biol. 2(3): 30.

Ashraf, M.Y., A.R. Awan, and K. Mahmood. 2012. Rehabilitation of saline ecosystems through cultivation of salt tolerant plants. Pak. J. Bot. 44: 69-75.

Barhoumi, Z., W. Djebali, A. Smaoui, W. Chaïbi and C. Abdelly. 2007. Contribution of $\mathrm{NaCl}$ excretion to salt resistance of Aeluropus littoralis (Willd) Parl. J. Plant Physiol. 164(7): 842-850.

El-Keblawy, A., Y.M. Al-Sodany and F.A. AlHadad. 2009. Effects of time of seed maturation on dormancy and germination requirements of Sporobolus spicatus
(Vahl) Kunth, a native desert grass of the United Arab Emirates. Grassland Sci. 55(1): 11-17.

Environment Agency Abu Dhabi. 2009. Abu Dhabi Water Resources Master Plan. Chapter. 2. In: Water availability and water use. Environment Agency, Abu Dhabi. p: 33-51.

Hu, L., Z. Huang, S. Liu, and J. Fu. 2012. Growth response and gene expression in antioxidant-related enzymes in two Bermuda grass genotypes differing in salt tolerance. J. Am. Soc. Hort. Sci. 137(3): 134-143.

Khan, M. A., \& Weber, D. J. (Eds.). (2006). Ecophysiology of high salinity tolerant plants (Vol. 40). Springer Science \& Business Media.

Marcum, K.B. 2006. Use of saline and nonpotable water in the turfgrass industry: Constraints and developments. J. Agric. Water Manage. 80(1): 132-146.

Mintenko, A., and R. Smith. 2001. Native grasses vary in salinity tolerance. p: 55-59. Turfgrass Golf Course Management.

Municipality of Abu Dhabi City. 2012. Irrigation System Operations and Maintenance. Volume 2A. Division 2. Section 2800 Part 4-B Watering requirement. p: 19. Abu Dhabi Municipality, UAE.

Murad, A. A., Al Nuaimi, H., and Al Hammadi, M. (2007). Comprehensive assessment of water resources in the United Arab Emirates (UAE). Water Res. Manage. 21(9): 1449-1463.

Naz, N., M. Hameed, and M. Ashraf. 2010. Eco-morphic response to salt stress in two halophytic grasses from the Cholistan desert, Pakistan. Pak. J. Bot. 42(2): 13431351.

Pessarakli, M. (2015). Using Bermudagrass (Cynodon dactylon L.) in urban desert landscaping and as a forage crop for sustainable agriculture in arid regions and combating desertification. Int. J. Water Res. Arid Env. 4, 08-14.

Pooya, E.S., A. Tehranifar, M. Shoor, and H. Ansari. 2013. Different growth responses of native turfgrass accessions to regulated deficit irrigation. Intl. J. Agron. Plant Prod. 4.

Romani, M., E. Piano and L. Pecetti. 2002. Collection and preliminary evaluation of 
native turfgrass accessions in Italy. Genet. Resour. Crop Evol. 49(4): 341-349.

Steel, R. G. D., Torrie, J. H., and DICKEY, M. (1980). A biometrical approach. Principles and Procedures of Statistics. National Library of Australia, Parkes Place Canberra, Australia. (www.trove.nla. gov.au).

Uddin, K.A.M.A.L., A.S. Juraimi, M.R. Ismail, R. Othman, and A.A. Rahim. 2009. Growth response of eight tropical turfgrass species to salinity. Afr. J. Biotechnol. 8(21).
Viggiani, R., V. Marchione, G. Potenza, D. Castronuovo, S. Fascetti, M. Perniola. 2015. Agronomic behaviour of some Cynodon dactylon ecotypes for turfgrass use in the Mediterranean climate. Italian J. Agron. 10(1): 1-8.

Zhang, Q., A. Zuk and K. Rue. 2013. Salinity tolerance of nine fine fescue cultivars compared to other cool-season turfgrasses. Sci. Hort. 159: 67-71. 